\title{
LA REGULACIÓN JURÍDICA DE LAS RELACIONES PATRIMONIALES DE LAS PAREJAS INTERNACIONALES EN LA UE
}

\author{
THE LEGAL REGULATION OF THE INTERNATIONAL COUPLES PROPERTY \\ RELATIONSHIPS IN THE EU
}

Ubaldo Greco *

\section{Resumen}

Cuando la pareja tiene una dimensión internacional por concurrir algún elemento extranjero, sea por la distinta nacionalidad o residencia de sus miembros integrantes, por la ubicación de los bienes que componen su patrimonio en diferentes Estados, etc., resulta sumamente conveniente establecer reglas armonizadoras para lograr soluciones uniformes ante los eventuales problemas que se puedan suscitar. De este modo, se potencia la seguridad jurídica y se favorece exponencialmente la libertad de circulación de las parejas internacionales. Para dar cumplimiento a dichos objetivos se promulgaron los Reglamentos (UE) 2016/1103 y 2016/1104 cuya plena aplicación ha tenido lugar a principios de 2019 y que, a pesar de haber sido gestados en el seno de la Unión Europea, en sus aspectos subjetivos están dirigidos a cónyuges y parejas de hecho provenientes también de terceros países.

Palabras clave: Unión Europea; Parejas internacionales; Reglamento (UE) 2016/1103, de 24 de junio de 2016; Reglamento (UE) 2016/1104, de 24 de junio de 2016; Regímenes económicos matrimoniales; Efectos patrimoniales de las uniones registradas; Reglas armonizadoras; Cooperación reforzada.

\begin{abstract}
When the couple has an international dimension due to some foreign element, either because of the different nationality or residence of its members or because of the location in various States of the goods that compose its patrimony, etc., it is highly desirable to lay down harmonized rules for achieving uniform solutions to any problems that might arise. In doing so, legal safeguard is enhanced and the freedom of movement of the international couples is extremely favored. In order to achieve those objectives, the Council Regulations (EU) 2016/1103 and 2016/1104 were promulgated, whose full implementation has taken place early 2019 and, even though they were conceived within the European Union, are aimed at spouses and domestic partnerships from anywhere in the world in their subjective aspects.
\end{abstract}

Keywords: European Union; International couples; Council Regulation (EU) 2016/1103 of 24 June 2016; Council Regulation (EU) 2016/1104 of 24 June 2016; Matrimonial property regimes; Property consequences of registered partnerships; Harmonised rules; Enhanced cooperation.

Investigador del Departamento de Derecho Internacional Privado de la Universidad de Sevilla. Master's degree in Law, Sapienza University of Rome. Actualmente cursa el Master of Arts (MA) in International Public Affairs, LUISS School of Government (Rome). 


\section{Introducción}

El día 8 de julio de 2016 se publicaron en el Diario Oficial de la Unión Europea el Reglamento (UE) 2016/1103 del Consejo, de 24 de junio de 2016, por el que se establece una cooperación reforzada en el ámbito de la competencia, la ley aplicable, el reconocimiento y la ejecución de resoluciones en materia de regímenes económicos matrimoniales (en adelante Reg. REM) ${ }^{1}$ y el Reglamento (UE) 2016/1104 del Consejo, de 24 de junio de 2016, por el que se establece una cooperación reforzada en el ámbito de la competencia, la ley aplicable, el reconocimiento y la ejecución de resoluciones en materia de efectos patrimoniales de las uniones registradas (en adelante Reg. EPUR) ${ }^{2}$.

Los dos Reglamentos, también conocidos como Reglamentos gemelos, tienen casi la misma estructura y numeración. Las diferencias se deben principalmente al estatus diferente de las parejas. Ambos logran la uniformidad referida a los efectos patrimoniales aplicables a los matrimonios o parejas registradas en los que concurran elementos transfronterizos.

Sin embargo, el resultado alcanzado no es enteramente satisfactorio, ya que para la aprobación de los Reglamentos fue necesario el recurso al procedimiento de cooperación reforzada $^{3}$. Esto representa una oportunidad perdida de realizar un importantísimo paso adelante hacia la definitiva comunitarización del derecho internacional privado, especialmente en el ámbito del derecho de familia.

En cuanto a las cooperaciones reforzadas, si hasta 2010 no se materializaron propuestas concretas, en los últimos años sí que se han iniciado algunas cooperaciones, especialmente en el Espacio de Libertad, Seguridad y Justicia. Ya podemos hablar de una Europa «a la carta» $\mathrm{y}$ «a dos velocidades», en la cual se manifiestan diversas actitudes de los Estados miembros en relación con la profundización en la integración, tendiendo algunos de ellos a pensar más sobre la base de su propio interés nacional y no comunitario.

\section{2. Ámbito de aplicación}

La normativa contenida en los Reglamentos requiere para su aplicación que quede totalmente perimetrado su ámbito de aplicación, el cual tiene cuatro vectores: espacial, personal, material y temporal.

Como cuestión previa es preciso aclarar que el legislador europeo, por un lado, no ofrece una definición de qué se entiende por matrimonio (de ahí que el Considerando 17 Reg. REM remita esta cuestión al Derecho nacional de los Estados miembros) y, por otro, establece una definición autónoma (esto es, restringida únicamente a los efectos del Reglamento 2016/1104) de "unión registrada" en el art. 3.1 a) Reg. EPUR, entendiendo por tal el "régimen de vida en común de dos personas regulado por ley, cuyo registro es obligatorio conforme a dicha ley y que cumple las formalidades jurídicas exigidas por dicha ley para su creación".

DOUE L 183/1-29, 8-VII-2016.

2 DOUE L 183/30-56, 8-VII-2016.

3 La cooperación reforzada es un procedimiento que permite que un mínimo de nueve países de la UE consigan una mayor integración en algunos ámbitos de competencias no exclusivas de la Unión de forma transparente y democrática, sin la participación de los demás países de la UE. Sin embargo, los Estados no participantes en la cooperación tienen las puertas abiertas para adherirse a ella en todo momento, siempre que respeten la decisión inicial y las posteriores medidas. 
Fácil es suponer que este punto ha constituido, precisamente, la manzana de la discordia entre los Estados miembros en la fase de aprobación de los Reglamentos, dadas las distintas concepciones que existen en unas materias tan sensibles como son el matrimonio y las uniones de hecho, lo que provoca que algunos de aquellos no admiten la posibilidad de uniones matrimoniales y/o extramatrimoniales entre personas del mismo sexo.

Preciso es, también, referirnos al carácter transfronterizo del litigio como presupuesto de aplicación de ambos Reglamentos, tal y como se recoge en los respectivos Considerandos 14.

\section{1 Ámbitos espacial y personal}

Al haber sido gestados ambos instrumentos con el sistema de la cooperación reforzada, solo serán aplicables a los Estados que se hayan sometido al mismo, sin perjuicio de que este ámbito espacial se ensanche a medida que se vayan produciendo sucesivas adhesiones, según el Considerando 13 de ambos Reglamentos. Los Estados miembros que participan en la cooperación reforzada son: Alemania, Austria, Bélgica, Bulgaria, Chipre, Croacia, Eslovenia, España, Finlandia, Francia, Grecia, Italia, Luxemburgo, Malta, los Países Bajos, Portugal, la República Checa y Suecia.

Dentro de los territorios de los Estados miembros que se encuentren vinculados por los Reglamentos, la aplicación de los mismos, desde el punto de vista personal, no presenta limitación alguna y se extiende a todas las personas, con independencia de cuál sea la nacionalidad que ostenten o de la residencia que tengan los cónyuges o los integrantes de las uniones registradas o las terceras personas que se relacionen económicamente con ellos.

De este modo, los Estados integrantes de la cooperación reforzada pueden aplicar la normativa de dichos Reglamentos tanto a nacionales de otros Estados miembros de la UE que no se hayan integrado en dicha cooperación, como a personas que sean nacionales o estén domiciliadas en terceros Estados.

\section{2 Ámbito material}

El paralelismo que existe entre ambos Reglamentos queda patente también en el ámbito material.

De entrada, el art. 3.1 a) Reg. REM define el régimen económico matrimonial como "el conjunto de normas relativas a las relaciones patrimoniales entre los cónyuges y con terceros, como resultado del matrimonio o de su disolución", mientras que el art. 3.1 b) Reg. EPUR entiende por efectos patrimoniales de las uniones registradas "el conjunto de normas relativas a las relaciones patrimoniales de los miembros de la unión registrada entre sí y con terceros, como resultado de la relación jurídica creada por el registro de la unión o su disolución".

Las nociones clave de "régimen matrimonial entre cónyuges y "efectos patrimoniales de las uniones registradas", se construyen, pues, a partir de nociones autónomas válidas a los solos efectos de aplicación de los respectivos Reglamentos, con independencia de que coincidan o no con las internas o sustantivas de los ordenamientos de los Estados partícipes en la cooperación, constituyendo el ámbito de aplicación positivo.

El ámbito material de los dos Reglamentos es bastante omnicomprensivo y abarca no solo los aspectos relativos a la gestión cotidiana de los bienes de los cónyuges o miembros de 
la pareja registrada, sino que también los relacionados con la liquidación como consecuencia de la separación o fallecimiento de los cónyuges o miembros de la unión registrada.

Además, hay que tener en cuenta que quedarían incluidos en el ámbito de aplicación del Reg. REM las normas del llamado régimen económico matrimonial primario y secundario. La circunscripción del ámbito material del Reglamento REM, en este sentido, no se recoge expresamente en ninguno de sus preceptos, pero se deduce del Considerando 18. Dada la distinta naturaleza jurídica de las uniones de hecho registradas, no se contiene en el Reg. EPUR ninguna previsión legal equiparable a la que se acaba de enunciar. No obstante, la posibilidad de que el conjunto de normas comprensivas de los efectos patrimoniales de las uniones registradas proceda tanto de la ley, como del acuerdo entre los miembros de la unión, aparece implícita en el art. 3.1. c) Reg. EPUR donde define las "capitulaciones de la unión registrada" en los mismos términos que el art. 3.1. b) Reg. REM establece para el matrimonio. En sentido negativo las materias excluidas son, en primer lugar, las que tienen un carácter eminentemente público: las cuestiones fiscales, aduaneras y administrativas (respectivos arts. $1.1)$.

A continuación, ambos Reglamentos realizan exclusiones pormenorizadas de cuestiones que, a pesar de tener naturaleza privada, carecen del carácter disponible ínsito en lo relativo al régimen económico (respectivos arts. 1.2):

a) la capacidad jurídica de los cónyuges o miembros de la unión registrada; b) la existencia, validez y reconocimiento del matrimonio o de la unión registrada ${ }^{4}$; c) las obligaciones de alimentos $^{5}$; d) la sucesión por causa de muerte de uno de los cónyuges o de los miembros de la unión registrada6; e) la seguridad social; f) el derecho de transmisión o ajuste entre los cónyuges o miembros de la unión registrada en caso de divorcio, separación judicial o anulación del matrimonio (disolución o anulación en el caso de unión registrada) de los derechos de pensión de jubilación o de invalidez devengados durante el matrimonio (o vigencia de la unión registrada) y que no hayan dado lugar a ingresos en forma de pensión durante el matrimonio o mientras haya durado la unión registrada ${ }^{7}$; g) la naturaleza de los derechos reales sobre un bien; h) cualquier inscripción de derechos sobre bienes muebles o inmuebles, incluidos los requisitos legales para llevarla a cabo, y los efectos de la inscripción o de la omisión de la inscripción de tales derechos en un registro.

\section{3 Ámbito temporal}

Siguiendo una pauta habitual en las medidas adoptadas en el campo de la cooperación judicial en materia civil, los Reglamentos distinguen dos momentos temporales netamente diferenciados: el de su entrada en vigor y el de su aplicación.

Este interregno de tiempo ha servido para que los Estados integrantes de la cooperación reforzada pudieran adecuar sus respectivas legislaciones internas. Con respecto al primero, dichos instrumentos reglamentarios están en vigor desde el día 29 de julio de 2016, es decir, a los veinte días de ser ambos publicados en el Diario Oficial de la Unión Europea.

\footnotetext{
4 Véanse Considerandos 64 Reg. REM y 63 Reg. EPUR.

5 Reguladas en el Reglamento (CE) 4/2009 del Consejo, de 18 de diciembre de 2008.

6 Asimismo, disciplinada en el Reglamento (UE) 650/2012, del Parlamento Europeo y del Consejo, de 4 de julio de 2012.

7 Véanse Considerandos 23.
} 
No obstante, la aplicación completa de los Reglamentos se produjo el 29 de enero de 2019, ex respectivos arts. 70. 2. Tal disposición implica que las nuevas normas uniformes solo se aplicarán "a las acciones judiciales ejercitadas, a los documentos públicos formalizados o registrados y a las transacciones judiciales aprobadas o celebradas a partir del 29 de enero de 2019" (respectivos arts. 69. 1).

Finalmente, las normas del Reglamento que regulan la ley aplicable quedan circunscritas en su ámbito de aplicación temporal a los cónyuges o integrantes de la pareja que hayan contraído matrimonio o registrado su unión (o establecido la ley aplicable a su régimen patrimonial) con posterioridad al 29 de enero de 2019 (respectivos arts. 69. 3).

Está claro que, si en el futuro otros Estados miembros se integran en la cooperación reforzada, los Reglamentos les serán aplicables a partir de la fecha de la Decisión que autorice la incorporación (respectivos arts. 70. 2).

\section{Soluciones propuestas}

La armonización establecida se dirige a lograr la seguridad jurídica en las relaciones transfronterizas dando respuesta a los tres grandes problemas que se pueden presentar en las relaciones jurídicas privadas internacionales: la determinación de la competencia judicial internacional; el señalamiento de la ley aplicable; el establecimiento de los mecanismos adecuados para el reconocimiento y ejecución de resoluciones judiciales y la aceptación y ejecución de documentos públicos y transacciones judiciales.

\subsection{Competencia judicial internacional}

Se parte de la premisa de que ambos Reglamentos potencian e incitan la posibilidad de que las partes resuelvan amistosa y extrajudicialmente el asunto relativo a sus relaciones económicas.

Las denominadas normas de competencia figuran en los respectivos Capítulos II y aclaran cuál es el órgano jurisdiccional competente para conocer de los asuntos que se susciten sobre la materia regulada en los Reglamentos REM y EPUR. Previamente, los Reglamentos gemelos dan una definición muy amplia de lo que se entiende por órganos jurisdiccionales (respectivos arts. 3.2), refiriéndose también a las autoridades y a los profesionales del Derecho que ejerzan funciones jurisdiccionales o que actúen por delegación de un órgano jurisdiccional, como puede ser el caso de los notarios.

Aclarado este punto, es necesario asumir sin ambages que los Reglamentos REM y EPUR usan dos técnicas distintas para determinar los respectivos tribunales de los Estados miembros competentes, aunque contemplan los mismos tipos de foros: en primer lugar, se prevé un criterio de conexidad y economía procesal allí donde sea posible; en según término, y únicamente cuando no haya conexidad o esta no sea aplicable, se hace referencia a un complejo sistema de foros, en el que algunos elementos se relacionan de forma alternativa y otros de manera subsidiaria.

La finalidad perseguida es que, en la medida de lo posible, los diferentes procedimientos que pudieran sustanciarse en Derecho de Familia sean conocidos por los órganos jurisdiccionales de un único Estado miembro, lo que requiere una concordancia por 
vía de remisión, tal y como establecen los arts. 4 y 5 de ambos instrumentos.

Naturalmente, la condición para que se opere la concentración de asuntos es que el órgano jurisdiccional que conozca de la sucesión (respectivos arts. 4) o de la crisis matrimonial o disolución o anulación de la unión registrada (respectivos arts. 5) pertenezcan a Estados que formen parte de la cooperación reforzada y, lógicamente, que ambos tipos de procesos no hayan concluido cuando surja la controversia en torno a los efectos patrimoniales del matrimonio o de las uniones de hecho registradas. En caso contrario, la competencia se determinará sobre la base de los foros establecidos en los siguientes artículos (respectivos arts. 6-11).

Los artículos 4 Reg. REM y Reg. EPUR, que coordinan los Reglamentos de que se trata con el Reglamento (UE) 650/2012 sobre las sucesiones mortis causa internacionales, establecen que los órganos jurisdiccionales que tengan competencia para la sucesión mortis causa conocerán también de los asuntos relativos al régimen económico matrimonial y a los efectos patrimoniales de las uniones registradas, por estar relacionados con esa sucesión. Se intenta de esta manera perseguir la coherencia del sistema de Derecho Procesal Civil Internacional de la Unión Europa.

Este automatismo se conserva, con algunas excepciones, en el art. 5 Reg. REM. Y precisamente, se dispone que el tribunal competente para conocer de un proceso relativo al régimen económico matrimonial ha de ser aquel que esté conociendo sobre la disolución del vínculo conyugal (divorcio, separación judicial o anulación del matrimonio) en virtud del Reglamento Bruselas II bis ${ }^{8}$. Sin embargo, y a diferencia de lo que ocurre en el caso de conexión con un proceso sucesorio, esta regla general puede ceder en favor de otros foros previstos en el Reg. REM, puesto que, como prevé el artículo 5.2 del Reg. REM, hay cuatro casos en los que la vis attractiva del proceso matrimonial respecto del proceso relativo al régimen económico matrimonial requiere del acuerdo entre los cónyuges; si este acuerdo no concurre, el tribunal que conoce del proceso matrimonial no atraerá hacia sí la competencia para el litigio relativo al régimen económico, que se determinará entonces a través de los foros contenidos en los artículos 6 a 11 del Reg. REM (Peiteado Mariscal, 2017, p. 318). Por lo que respecta a dicho acuerdo, el artículo 5.3 Reg. REM establece de forma expresa que si este se celebra antes de que se requiera al órgano jurisdiccional que resuelva sobre el régimen económico matrimonial, dicho acuerdo deberá reunir los requisitos del artículo 7.2 Reg. REM.

En cambio, téngase en cuenta que la competencia para conocer de un proceso relativo a los efectos patrimoniales de la unión registrada no es automáticamente atraída por el Estado cuyos tribunales conocen del proceso dirigido a disolver o anular la unión: se necesita siempre que los integrantes de la unión así lo acuerden, ex art. 5 Reg. EPUR. El motivo por el que la conexión se encuentra condicionada a dicho acuerdo se ha explicado partiendo de la ausencia de un Reglamento relativo a la competencia para disolver o anular uniones de hecho, lo que provoca la incapacidad del legislador europeo de asegurar la adecuación del foro relativo al conocimiento de procesos sobre efectos patrimoniales con los determinados en las diversas legislaciones internas para el conocimiento de la disolución o anulación de la unión (Peiteado Mariscal, 2017, pp. 323-324).

Cuando ningún órgano jurisdiccional de un Estado miembro tenga competencia con

8 Reglamento (CE) n ${ }^{\circ}$ 2201/2003 del Consejo, de 27 de noviembre de 2003. 
arreglo a los artículos 4 o 5 (Reg. REM y Reg. EPUR) o en otros casos distintos de los previstos en dichos artículos, el tribunal competente se determinará con arreglo a lo prescrito en los respectivos artículos 6. Ambos recogen una lista de foros jerárquicamente enumerados, comenzando por la residencia habitual de los miembros de la pareja en el momento de la interposición de la demanda. En defecto, se hace referencia a la última residencia habitual si uno de ellos aún resida allí o, en tercer lugar, la residencia habitual del demandado. El cuarto criterio es la nacionalidad común de los cónyuges o de los miembros de la unión registrada en el momento de la interposición de la demanda. Por último, y tan solo en el Reglamento EPUR, se identifica un quinto foro según el cual, en defecto de los anteriores, serán competentes los órganos jurisdiccionales del Estado miembro conforme a cuya ley se haya creado la unión registrada.

Con el fin de acrecentar la previsibilidad y la libertad de elección de las partes, los respectivos artículos 7 contemplan la posibilidad de acordar la elección del foro para los casos contemplados en los artículos 6 (y por lo tanto la cláusula de elección es válida solo si no son aplicables los artículos 4 y 5, por lo que se ha de verificar su existencia en defecto de los mismos y antes de la aplicación de los arts. 6). Específicamente, el art. 7 Reg. REM permite la sumisión expresa únicamente a los tribunales de dos Estados: los órganos jurisdiccionales del Estado miembro cuya ley sea aplicable al régimen económico matrimonial ${ }^{9}$ o bien los órganos jurisdiccionales del Estado miembro en el que se haya celebrado el matrimonio, aspirando de este modo a lograr la deseable equiparación fórum - ius. Análogamente, el art. 7 Reg. EPUR permite la atribución de la competencia expresa a las autoridades del Estado miembro cuya ley es aplicable con arreglo a los artículos 22 y 26.1, es decir la ley del Estado de residencia habitual o la ley del Estado de la nacionalidad de cualquiera de los miembros o futuros miembros de la unión registrada (teniendo en ambos casos en cuenta el momento en que se celebre el acuerdo), así como la ley del Estado conforme a cuya ley se haya creado la unión registrada.

Los siguientes artículos 8 permiten que la competencia internacional de los tribunales de los Estados miembros se fije mediante sumisión tácita del demandado, es decir mediante su comparecencia, siempre que esta no tenga como objetivo la impugnación de la competencia, ni en los casos regulados por los arts. 4 o 5.1 Reg. REM y 4 Reg. EPUR.

Ahora bien, es necesario que el tribunal al que la sumisión tácita del demandado le otorgaría competencia verifique que el demandado sea informado de su derecho a impugnar la competencia y, al mismo tiempo, sea consciente de las consecuencias de su comparecencia o incomparecencia. Sin embargo, para que sea válida la aplicación de los arts. 7 y 8 es necesario que el derecho aplicable o, en el caso de sumisión expresa, el lugar de la celebración del matrimonio o el lugar conforme a cuya ley se haya creado la unión registrada, se localicen en Estados miembros vinculados por los Reglamentos (Quinzá Redondo, 2017, p. 198).

Los Reglamentos permiten, por otro lado, inhibirse al órgano jurisdiccional inicialmente competente, sin dilación indebida, si se considera que en su Derecho nacional no está reconocido el matrimonio que requiere de una solución para la cuestión del régimen económico matrimonial o la institución de la unión registrada. Para obviar situaciones de

9 Es decir, la ley del Estado de residencia habitual o de la nacionalidad de cualquiera de los cónyuges o futuros cónyuges con respecto al momento de la celebración del acuerdo y la ley del Estado de la primera residencia habitual común de los cónyuges tras la celebración del matrimonio o, en su defecto, de la nacionalidad común de los cónyuges en el momento de la celebración del matrimonio, ex artículos 22, 26.1 a) o 26.1 b) Reg. REM. 
denegación de justicia, el legislador europeo ha establecido algunos foros de competencia alternativa, recogidos en los artículos 9 Reg. REM y Reg. EPUR. Si las partes están de acuerdo, la competencia alternativa se puede atribuir a las autoridades de otro Estado miembro, estableciéndose distintas soluciones en atención al foro del Reglamento que haya fundamentado la competencia judicial internacional del órgano que conoce del asunto. Sin embargo debe prestarse atención a una importante excepción: el Estado miembro del órgano jurisdiccional requerido seguirá siendo competente siempre que reconozca una resolución (dictada anteriormente) en materia de divorcio, separación o disolución del matrimonio o de la unión registrada. En ese caso, nada se opone a que pueda también conocer acerca de uno de los efectos más relevantes de la disolución, cual es la cuestión del régimen económico matrimonial o de los efectos patrimoniales.

Incluso podría pasar que ningún Estado miembro sea competente en aplicación de los artículos anteriores. Se trata de un caso muy improbable con respecto al cual, de todos modos, los Reglamentos gemelos han dado respuesta introduciendo una hipótesis de competencia subsidiaria mediante los respectivos artículos 10 . Según lo previsto en ambos Reglamentos, se garantiza el acceso a la justicia de las partes interesadas ante los órganos jurisdiccionales del Estado miembro en el que uno o ambos miembros de la pareja posean el bien o los bienes inmuebles ${ }^{10}$. Debe tratarse, como es obvio, de bienes inmuebles situados en Estados que participan de la cooperación reforzada.

En estos casos, los órganos jurisdiccionales solo tendrán competencia para resolver sobre el bien o los bienes inmuebles de que se trata, limitando de hecho el litigio a uno o algunos bienes sin considerar todos aquellos comprendidos en el patrimonio de la pareja.

Dicha disposición es controvertida, considerando que uno de los objetivos declarados de los Reglamentos en examen es concentrar asuntos bajo un mismo tribunal, por lo que su admisión puede provocar una no deseada fragmentación en la solución, es decir, que existan tantas autoridades competentes como bienes tuvieran las parejas en los diferentes Estados (Rodriguez Benot, 2012, p. 565). Pero tampoco estamos ante un caso aislado, puesto que los Reglamentos prevén otra hipótesis en la que es posible que el litigio se limite a solo algunos bienes. Efectivamente, en los supuestos de fallecimiento de uno de los miembros de la pareja, los respectivos artículos 13 permiten la exclusión, a instancia de una de las partes, de aquellos bienes (de la herencia del causante) situados en un tercer Estado si hubiera riesgo de no reconocimiento de la decisión que afecta a dichos bienes.

Los respectivos artículos 11 introducen un foro de necesidad que será de aplicación en circunstancias excepcionales, cuando no sea posible acudir a ninguno de los órganos jurisdiccionales basándose en los artículos anteriores.

Por último, los artículos 12 a 19 de ambos Reglamentos contienen normas de competencia de orden técnico-procesal cuyo objetivo es evitar que se dicten resoluciones inconciliables en Estados miembros distintos ocupándose de la verificación de oficio y de las cuestiones de litispendencia y conexidad internacionales.

\subsection{Ley aplicable}

El Capítulo III de ambos Reglamentos está dedicado a la resolución de la cuestión de

10 Esta disposición está inspirada en el artículo 10.2 del Reglamento (UE) nº 650/2012. 
la legislación que se debe aplicar en cada caso específico. A pesar de la coincidencia numérica de los artículos de este capítulo en los Reglamentos REM y EPUR, no siempre se establecen reglas totalmente equiparables, debido a la diferente naturaleza jurídica de la relación matrimonial y extramatrimonial de la que se ocupa cada uno.

Sin embargo, las normas de conflicto se vertebran en torno a dos principios básicos: el de la universalidad y el de la unidad de la ley aplicable.

Según el primero, puede resultar potencialmente aplicable la ley de cualquier Estado, aunque no se encuentre vinculado por los Reglamentos gemelos (respectivos arts. 20). Ello implica la desaparición de la frontera entre Estados parte de la cooperación reforzada y aquellos otros que no se han vinculado, pues la ley que resulte finalmente aplicable puede, indistintamente, ser tanto la de unos como la de otros y, por supuesto, la de un Estado no miembro de la Unión europea.

La unidad viene consagrada de forma clara en los respectivos arts. 21, que extienden la aplicación de la ley resultante a todos los bienes englobados en el régimen económico matrimonial o en los efectos patrimoniales de las uniones registradas, al margen del lugar donde se encuentren. Se justifica tal opción por razones de seguridad jurídica para evitar la fragmentación, "con independencia de la naturaleza de los bienes y de si los bienes están situados en otro Estado miembro o en un tercer Estado"11.

El loable deseo de favorecer la unidad del patrimonio con respecto a la unidad del pasivo puede verse empañado por la eventual descoordinación que se puede producir entre la ley aplicable, según los Reglamentos que se analizan, con la lex rei sitae, punto de conexión general para determinar la ley reguladora de las cuestiones atinentes a la propiedad y demás derechos reales, en especial, la exigencia de una determinada forma y publicidad (Quinzá 21Redondo, 2017, p. 194). aplicable:

Previamente veremos las cuestiones a las que se extiende la regulación de la ley

\section{1) Ámbito de la ley aplicable.}

Los respectivos arts. 27 se ocupan de enumerar las materias acogidas en la regulación de la ley aplicable, en términos semejantes y con carácter meramente ejemplificativo (como lo demuestra la expresión "entre otras cosas" utilizada en ambos artículos). Para ello hacen una neta distinción entre las relaciones ad intra y ad extra.

En las primeras quedarían incluidos los aspectos patrimoniales de las relaciones económicas entre los cónyuges o miembros de la unión registrada, tanto durante la vigencia de las respectivas relaciones como en el momento de su extinción. Mientras que en los apartados f) se trata de dichas relaciones en su vertiente externa, esto es, con los terceros. A estas cuestiones se añade en los respectivos apartados g) la validez material de las capitulaciones matrimoniales y de las capitulaciones de la unión registrada, para la que se remite a lo establecido en el ordenamiento estatal que resulte aplicable.

El campo de relaciones externas ha motivado el diseño, por parte del legislador europeo, de una norma tuitiva para proteger los derechos de los terceros de buena fe que se

11 Considerando 42 Reg. REM y 43 Reg. EPUR. 
relacionen con uno o ambos cónyuges o miembros de la unión registrada. Para ello se veda la posibilidad de invocar en un litigio la ley aplicable, por parte de estos, frente a un tercero a no ser que se demuestre, con base en una serie de presunciones que se establecen a continuación, que dicho tercero "conociera o actuando con la debida diligencia, debiera haber tenido conocimiento de dicha ley".

En el caso de que, finalmente, no pudiera ser invocada la ley que regula los efectos patrimoniales, ambos Reglamentos fijan las oportunas conexiones para regular las relaciones externas (respectivos arts. 28).

2) Determinación de la ley aplicable.

Hechas estas precisiones, la arquitectura de los Reglamentos en torno al problema de la ley aplicable se monta sobre dos pilares: la determinación de la ley aplicable hecha por las partes en uso de la autonomía de la voluntad y el establecimiento de un sistema de normas de conflicto subsidiarias para la hipótesis en la que los respectivos protagonistas de estas uniones matrimoniales o extramatrimoniales no hayan hecho uso de la professio iuris.

En lógica sintonía con lo que sucede en las legislaciones internas de los Estados miembros de la UE, la determinación por los cónyuges o miembros de la unión registrada de las reglas para regular sus relaciones económicas tiene prioridad sobre las impuestas por el legislador, pues son aquellos los que mejor conocen y pueden defender sus intereses de tal índole, de ahí la importancia de que la elección sea informada. Además, con ello se evita que los tribunales tengan que decidir sobre esta materia, por eso que el legislador europeo, en sus últimas reglamentaciones, ha extendido tal posibilidad a ámbitos que tradicionalmente quedaban fuera del radio de acción de dicho principio ${ }^{12}$.

La consagración del principio en cuestión se encuentra en los respectivos arts. 22, que presentan ciertos matices diferenciales inevitables por la diferente situación de partida que acoge cada instrumento. Esta es la razón por la que en el primer párrafo del art. 22 Reg. EPUR se establece la prevención, de entrada, de que la ley elegida por ambos miembros reconozca efectos patrimoniales a la institución de la unión registrada ${ }^{13}$.

A continuación, en dichos artículos se determinan, alternativamente, las posibles leyes que se pueden elegir, ya que se trata de una autonomía de la voluntad conflictual limitada: la ley del Estado de la residencia habitual o de la nacionalidad de los cónyuges, miembros o futuros cónyuges o miembros de la unión registrada en el momento de celebración del acuerdo.

A estos tradicionales puntos de conexión se añade, para las uniones registradas, la ley del Estado conforme a cuya ley se haya creado la unión registrada.

La libertad de elección pivota, pues, en torno a la ley del lugar de residencia habitual, cuando así lo hagan constar por hallarse plenamente integrados en su nuevo entorno (posibilidad que no se debe descartar, ya que dados los flujos migratorios hay personas que salen de su país y no regresan jamás), o si lo prefieren la de su nacionalidad, con lo que se

12 Véase, en tal sentido, el art. 22 Reglamento de Sucesiones 650/2012, el art.5 Reglamento sobre ley aplicable a la separación y al divorcio 1259/2010 y el art. 8 Reglamento de Alimentos 4/2009.

13 Lo que se justifica "para evitar que la elección de ley carezca de efecto alguno, dejando a los miembros de la unión registrada en un vacío legal" (ex Considerando 44 Reg. EPUR). 
aseguran, en cierta medida, que la sentencia que recaiga va a ser reconocida y ejecutada en su país de origen ${ }^{14}$. Acotada de este modo la elección, lo que no existe es limitación alguna en cuanto al momento temporal en el que se puede llevar a cabo, así como en el número de cambios que eventualmente se pueden realizar (siempre que la elección recaiga sobre los mismos ordenamientos jurídicos: nacionalidad o residencia habitual de cualquiera de los miembros o, únicamente para las uniones registradas, ley del Estado conforme a la que se hayan creado). Dichos cambios tendrán eficacia ex nunc, salvo pacto en contrario, en cuyo caso siempre quedarán salvaguardados los derechos de terceros.

Los límites vuelven a aparecer con la imposición de ciertos requisitos formales en los respectivos arts. 23 (para los acuerdos de elección de ley aplicable) y 25 (para las capitulaciones matrimoniales o de la unión registrada). En efecto, siguiendo la estela dejada por los Reglamentos precedentes se exige, con carácter general, que el acuerdo se materialice por escrito fechado y firmado por ambos integrantes, aunque se extiende tal soporte a los medios electrónicos que puedan proporcionar "un registro duradero del acuerdo".

Los requisitos formales adicionales que se puedan establecer dependen de dónde tengan su residencia habitual los cónyuges o miembros de la unión registrada en el momento de la celebración del acuerdo. Si ambos la tienen en el mismo Estado miembro (se refiere solo a los Estados participantes en la cooperación reforzada) que los impone, dichos requisitos se deben observar, lo mismo que si es uno solo de los esposos o miembros de la unión registrada el que posee la residencia en dicho Estado miembro. Si la tienen en diferentes Estados miembros cuyas leyes exigen diversos requisitos, basta con que cumplan los requisitos de una de las dos leyes.

Las mismas soluciones se arbitran para el cumplimiento de la validez formal de las capitulaciones matrimoniales, con la evidente diferencia de que el lugar de residencia se toma en consideración en el momento de la celebración de las capitulaciones matrimoniales o de la unión registrada y con la sola adición de la necesidad del cumplimiento de los eventuales requisitos adicionales establecidos por la ley aplicable al régimen económico matrimonial o a los efectos patrimoniales, esto es por la ley sustantiva que los regule. No se exige, sin embargo el cumplimiento de los requisitos formales adicionales que pueden venir impuestos por las leyes de terceros Estados.

Finalmente, en los arts. 24 de ambos Reglamentos se articula el régimen al que se somete la validez material y el consentimiento de estos acuerdos remitiendo a la ley elegida, ex respectivos arts. 22, siempre que dicha elección fuese válida.

Con carácter excepcional se admite que uno de los miembros del matrimonio o de la unión registrada pueda invocar la ley del país de su residencia habitual en el momento de sustanciar el asunto ante el órgano jurisdiccional para probar la ausencia de su consentimiento, cuando no resultase razonable que el efecto de tal conducta quedara sometido a la ley elegida por ambos (respectivos arts. 24.2).

La norma de conflicto establecida con carácter subsidiario para la hipótesis de que las

14 Lógicamente, cuanto más internacional sea la pareja más se abre el abanico de elección de leyes, teniendo en cuenta que la consideración de los sujetos con doble nacionalidad es una cuestión que se remite al Derecho nacional, aunque dicha consideración "no debe tener ninguna incidencia en la validez de la elección de la ley aplicable" de conformidad con los respectivos Reglamentos (ex Considerando 50 Reg. REM y 49 Reg. EPUR). 
partes no hagan uso de la professio iuris o bien esta no sea válida es la que presenta mayor disparidad en su regulación por los dos Reglamentos, aunque numéricamente se utilice en ambos el art. 26. A estos efectos, el Reg. EPUR designa, como una única ley, la del Estado conforme a la que se haya creado la unión registrada. En cambio, el Reg. REM establece tres normas en cascada, aplicables jerárquicamente una en defecto de la otra. Y estas son la ley del Estado de la primera residencia habitual común de los cónyuges tras la celebración del matrimonio o, en su defecto, la de la nacionalidad común en el momento de la celebración del matrimonio (con la previsión de que si tuvieran más de una nacionalidad en común no opera este punto de conexión, para evitar "favorecer" una nacionalidad sobre otra) o, por último, la del país que presente la vinculación más estrecha con ambos cónyuges en este mismo momento, que actúa como conexión de cierre.

La regla general que se contiene en ambos Reglamentos, aunque con distintos puntos de conexión, ofrece en los dos la misma excepción, que es la posibilidad de aplicar la ley de un Estado distinto al de la primera residencia habitual común después de la celebración del matrimonio o del Estado en el que se haya creado la unión registrada, cuando así lo acuerde el juez a petición de cualquiera de los integrantes del matrimonio o de la unión registrada, siempre que en este último caso la ley de dicho Estado les atribuya efectos patrimoniales. Se conjura de este modo el peligro que puede suponer el que los integrantes de estas uniones, matrimoniales y extramatrimoniales, ya no se sientan identificados con la ley del país establecida como regla general (que toma como referente temporal el momento de la celebración del matrimonio o de la constitución de la unión registrada). De ahí que se otorgue la posibilidad de activar esta cláusula de escape dando lugar a la aplicación de la ley del Estado de la última residencia habitual común de los cónyuges o miembros de la unión registrada.

Ahora bien, para que entre en juego dicha excepción es preciso que la parte que lo solicita demuestre, cumulativamente, dos circunstancias de tipo fáctico, es decir, la mayor duración de la última residencia habitual común de la pareja en dicho Estado distinto y la planificación u organización de sus relaciones patrimoniales con base en la ley de ese otro Estado, requisito no exento de dificultad en cuanto a su prueba. En cualquier caso, se impone la necesidad de que los derechos de los terceros derivados de la ley de la residencia habitual común de los cónyuges o de la ley del Estado conforme a la que se haya creado la unión registrada no queden afectados negativamente y que no se hayan otorgado capitulaciones matrimoniales con anterioridad al establecimiento de su última residencia habitual común en el Estado distinto (respectivos arts. 26).

La gran complejidad que late en la excepción contemplada en los arts. 26 de ambos Reglamentos ha motivado una crítica desfavorable por parte de algunos autores, llegando a decir que "resulta claramente prescindible si lo que realmente se persigue es la previsibilidad y la seguridad jurídica" (Rodríguez Benot, 2019, p. 42).

3) Cuestiones comunes a todo tipo de leyes aplicables contenidas en los Reglamentos.

La autonomía de la voluntad de las partes, a pesar de cumplir con la función de fortalecer la seguridad jurídica en sus relaciones privadas transfronterizas vigorizando la mayor movilidad de los ciudadanos europeos, encuentra su límite en las llamadas leyes de policía y la excepción de orden público del foro.

En primer lugar, hemos de considerar la tradicional cláusula del orden público tal y 
como se regula en los respectivos arts. 31. Según dicha cláusula, si de la aplicación de las reglas de conflicto contenidas en el Reglamento resultara aplicable una ley extranjera que vulnera el orden público del foro, dicha ley será inaplicable. Como complemento a dicha prohibición estaría la imposibilidad de vulnerar las leyes de policía (respectivos arts. 30). Esta denominación comprende las disposiciones que cada Estado considera primordiales para velar por sus intereses públicos y que, por tanto, se imponen para su aplicación con independencia de cuál sea la ley que resulte aplicable, si bien dicha excepción ha de ser objeto de interpretación restrictiva para no truncar el objetivo general perseguido por ambos Reglamentos cual es el de la unidad de ley aplicable. Los Considerandos 53 Reg. REM y 52 Reg. EPUR señalan, como ejemplo de leyes de policía, las normas de carácter imperativo establecidas para la protección de la vivienda familiar.

La exclusión del reenvío viene claramente establecida en los respectivos arts. 32, que determinan que la remisión a la ley de un Estado se entiende hecha a su ley material, con exclusión de su sistema de normas de Derecho Internacional Privado. Con dicha previsión se corta de raíz la posibilidad de utilizar las normas de conflicto de dicho Estado y, por tanto, que surja, al menos, una segunda remisión a la ley de otro Estado, requisito indispensable para que exista el reenvío, como mecanismo propio de la fisonomía de las normas de conflicto.

En fin, los Reglamentos se hacen eco de la problemática que entrañan las hipótesis de Estados plurilegislativos donde la respuesta inicialmente dada por la norma de conflicto deviene incompleta, pues al tratarse de países en los que coexisten diferentes sistemas legislativos, se impone la necesidad de concretar el particular derecho aplicable.

Para resolver esta cuestión se distingue, en los respectivos arts. 33 y 34, entre los conflictos territoriales (que se dan en aquellos Estados que comprenden varias unidades territoriales con sus propias normas jurídicas en materia de régimen económico matrimonial o de efectos patrimoniales de las uniones registradas) y los interpersonales de leyes (presentes en los Estados con dos o más regímenes jurídicos o conjuntos de normas aplicables a diferentes categorías de personas en las materias acabadas de mencionar).

Respecto a los Estados plurilegislativos de base personal, se prevé que toda referencia a la ley de tales ordenamientos debe entenderse como una remisión al sistema jurídico de las normas en vigor en tal Estado, es decir, que habrá que estar en primer lugar a lo que establezcan sus propias normas de conflicto y, en su defecto, aplicar el régimen jurídico o conjunto de normas con el que los miembros de la pareja en cuestión tengan una conexión más estrecha. Para el primer tipo de Estados remite a sus propias normas internas en materia de conflicto de leyes la determinación de la específica unidad territorial pertinente. Y, en defecto de tales normas, se prevén diversas soluciones según cuál haya sido el punto de conexión empleado por la norma de conflicto. Si se ha utilizado el criterio de la residencia habitual, se aplicará la ley de la unidad territorial en la que los elementos personales tengan su residencia habitual. En el caso en que se haya empleado el punto de conexión de la nacionalidad de las partes, deberá tomarse en consideración la ley de la unidad territorial con la que los cónyuges o miembros de la unión registrada tengan la conexión más estrecha. En el resto de las situaciones tendrá aplicación la ley de la unidad territorial donde el elemento en cuestión se encuentre situado. En conexión con la hipótesis anterior, la regulación de los conflictos interterritoriales se cierra con la disposición contenida en los arts. 35 de ambos instrumentos que, interpretada a sensu contrario, permitiría la aplicación de los Reglamentos para los conflictos puramente interregionales (es decir, aquellos que se presentan exclusivamente entre unidades territoriales de un mismo Estado). 


\subsection{Reconocimiento y ejecución}

Gran parte de las medidas estudiadas hasta aquí van dirigidas a la obtención de una resolución que, por el escenario internacional en el que nos movemos, ha de surtir efecto en un Estado distinto de aquel cuyos órganos jurisdiccionales la dictaron. Asimismo, en muchas ocasiones, los documentos públicos y transacciones judiciales necesitan circular de un Estado a otro. El procedimiento diseñado por el legislador europeo para conseguir dicha finalidad se ha regulado en los Capítulos IV (en cuanto a las resoluciones judiciales) y V (por lo que respecta a los documentos públicos y transacciones judiciales), en un plano de total paralelismo entre ambos Reglamentos ${ }^{15}$.

Todo el sistema se articula en torno al principio básico de la confianza recíproca entre las diversas autoridades pertenecientes a los Estados que forman parte de la cooperación reforzada. Esto facilita al máximo el movimiento de la resolución, documento o transacción de un país a otro, y permite lograr lo que se ha dado en llamar "la quinta libertad comunitaria", o sea, la libre circulación de actos dentro del espacio judicial europeo.

Precisamente, se instaura el reconocimiento automático en sintonía con lo establecido en el resto de los Reglamentos europeos (respectivos art. 36.1).

Asimismo se reconoce la posibilidad, por parte del Estado miembro al que se solicita el reconocimiento, que se lleven a cabo dos tipos de controles: a título principal (de conformidad con el procedimiento previsto para la declaración de fuerza ejecutiva) y a título incidental.

Los motivos por los que se puede denegar el reconocimiento son los "clásicos": a) por contrariedad manifiesta con el orden público del Estado miembro en el que se solicita el reconocimiento; b) en presencia de resoluciones dictadas en rebeldía, cuando no se haya notificado la demanda o documento equivalente en tiempo y forma, salvo que el demandado no hubiera agotado sus posibilidades de defensa por no recurrir en el caso de que hubiera podido hacerlo; c) si la resolución fuere inconciliable con una resolución dictada en un procedimiento entre las mismas partes en el Estado miembro en el que se solicita el reconocimiento; d) si la resolución fuere inconciliable con una resolución dictada con anterioridad en un litigio, en otro Estado miembro o en un tercer Estado, entre las mismas partes con el mismo objeto, cuando esta última resolución reúna las condiciones necesarias para su reconocimiento en el Estado miembro en el que se solicita el reconocimiento. (respectivos arts. 37).

Igualmente, los Reglamentos prescriben la imposibilidad de controlar la competencia de los órganos jurisdiccionales del Estado miembro de origen y de proceder a una revisión en cuanto al fondo de las resoluciones dictadas por los mismos (respectivos arts. 39 y 40).

En ningún caso los órganos jurisdiccionales del Estado miembro de destino se pueden convertir en una segunda instancia, estando sus posibilidades de control limitadas, única y exclusivamente, al examen formal de los documentos presentados y a la apreciación de los eventuales motivos de denegación arriba expuestos.

15 Dada la limitación en la extensión del presente trabajo, me ceñiré al tema del reconocimiento y ejecución de las sentencias. 
Para obtener la ejecución de la resolución en el Estado de destino es necesaria una previa declaración de fuerza ejecutiva, de la que las sentencias extranjeras carecen. Sobre este punto los Reglamentos gemelos han roto con las últimas tendencias de los Reglamentos europeos que han suprimido el exequatur a estos efectos (concretamente el Reglamento de Bruselas I bis 1215/ 2012). Para conseguir dicha declaración de ejecutoriedad bastará con presentar los documentos previstos en los respectivos arts. 45 ante las autoridades del Estado miembro requerido. Y al hacerlo, el exequatur será concedido, ex respectivos arts. 47, y notificado tanto al solicitante como a la parte contra la que se haya solicitado la ejecución (respectivos arts. 48).

En esta fase el proceso se puede convertir en contradictorio, al abrirse la posibilidad de interponer recursos por cualquiera de las partes dentro del plazo de 30 días a partir de la oportuna notificación, ampliable a 60 si la parte contra la que se solicita la ejecución estuviera domiciliada en un Estado distinto de aquel en el que se haya dictado la declaración de fuerza ejecutiva (respectivos arts. 49.3).

Al mismo tiempo, también la resolución dictada sobre el recurso puede ser impugnada.

Por último, la declaración de fuerza ejecutiva se podrá denegar o revocar basándose en los motivos de denegación expuestos para el reconocimiento (respectivos arts. 51).

Además, hay que señalar que las disposiciones contenidas en ambos Reglamentos sobre reconocimiento y ejecución de resoluciones judiciales se extienden también a los documentos expedidos por las autoridades que ejerzan sus competencias por delegación, de conformidad con la definición de "órgano jurisdiccional" del art. 3 de ambos textos reglamentarios ${ }^{16}$.

\section{Valoración final}

Los flujos migratorios, la multiculturalidad y la facilidad para viajar de un lugar a otro del planeta son fenómenos que se imponen en la realidad social de nuestros días y que repercuten, decisivamente, en el ámbito de las relaciones familiares. Ante tales hechos el derecho reacciona, como no podía ser de otra manera, para dar respuesta a las problemáticas que plantean los nuevos retos sociales.

Sin restar valor a los enormes logros que los Reglamentos gemelos han llevado a la deseada armonización dentro del seno de la Unión Europea de una materia tan sensible, como es el Derecho de Familia, hay que señalar, no obstante, algunos puntos críticos o mejorables:

a) En el ámbito de aplicación de los respectivos Reglamentos podemos toparnos con los primeros problemas causados por el legislador europeo, pues al utilizar definiciones sumamente amplias tanto de lo que se entiende por "régimen económico matrimonial" y del concepto de "efectos patrimoniales de las uniones registradas", como del contenido de las exclusiones, será necesario llevar a cabo previamente una labor de calificación a nivel interno, con la complejidad que en no pocas ocasiones lleva aparejada dicha figura.

16 En ningún caso el reconocimiento y ejecución de resoluciones implica el reconocimiento del matrimonio o de la unión registrada que dio lugar a la resolución (Considerando 64 Reg. REM y 63 Reg. EPUR). 
b) En cuanto a la determinación del órgano jurisdiccional competente para dirimir los eventuales litigios, el criterio de conexión utilizado en los respectivos arts. 4 y 5 resulta sumamente acertado ${ }^{17}$, así como la posibilidad de utilizar la autonomía de la voluntad, aunque de forma limitada. Más complejo es el mecanismo excepcional de inhibición regulado en los arts. 9 de ambos Reglamentos. Conviene destacar asimismo que, finalmente, el legislador evidencia el deseo de establecer un sistema internacional completo, buscando la supresión íntegra de remisión a las normas nacionales en lo que a competencia se refiere y estableciendo un foro subsidiario y otro de necesidad.

c) Al igual que para la fijación de la competencia judicial, una de las principales novedades introducidas por los Reglamentos es la actuación de la autonomía de la voluntad de los miembros de la pareja para designar la ley aplicable.

Los puntos de conexión normalmente utilizados son la residencia habitual y la nacionalidad. Con respecto al primero, el legislador europeo sigue sin dar un concepto claro del mismo. En cuanto a la nacionalidad, se excluye de su ámbito de aplicación lo relativo a la doble nacionalidad. Ambas son lagunas que pueden conllevar inseguridad e incertidumbre jurídica. Conectando ambos aspectos, el de la competencia y el de la ley aplicable, se aprecia una clara tendencia a unificar el forum y el ius, lo que es muy de agradecer en el ámbito del Derecho de Familia, donde las cuestiones procesales y sustantivas están tan íntimamente unidas.

d) Finalmente, en cuanto al reconocimiento y ejecución, se observa que el mantenimiento del exequatur puede suponer un retroceso en la aplicación práctica de los Reglamentos y pugna con la opinión legislativa favorable a su supresión desarrollada por el legislador comunitario en los últimos Reglamentos, aunque con diferentes matices e intensidades.

No obstante, por encima de todas estas apreciaciones, los Reglamentos examinados suponen la culminación de la comunitarización de todos los sectores del Derecho Internacional Privado de la Familia, Sucesiones y Obligaciones Alimenticias, sin dejar prácticamente resquicios regulatorios. Por ello es de esperar que las deficiencias y complejidades que presentan, la eventual descoordinación con otros Reglamentos sumamente relacionados con el aspecto patrimonial de las parejas (concretamente, el Reg. Bruselas II bis, el Reg. sobre sucesiones y el Reg. Roma III) e, incluso, las disfunciones que se aprecian dentro de los mismos (como es el caso de la desconexión del art. 26 con el art. 6 para fijar la residencia habitual y la nacionalidad en el Reg. REM), sean corregidas a través de una buena praxis por parte de todos los operadores jurídicos.

17 Téngase en cuenta que la concentración de asuntos puede alcanzar su máxima expresión en la esfera familiar cuando se utilice la prórroga de la competencia del art. 12.1 Reg. Bruselas II bis. En ese caso, las cuestiones relativas a la responsabilidad parental vinculadas a una demanda de separación, nulidad o divorcio de un matrimonio serían juzgadas por el mismo órgano jurisdiccional que conozca de aquella, (determinado según el art. 3 de dicho Reglamento), cuestiones a las que se añadiría lo relativo al derecho de alimentos (art. 3 del Reglamento 4/2009 en materia de obligaciones de alimentos), así como el reparto y liquidación de los bienes del matrimonio por imperativo del art. 5 Reg. REM. Para las uniones de hecho registradas no existe regulación europea para su disolución, por lo que habrá que estar, en principio, a la normativa interna o autónoma. No así para las obligaciones de alimentos a la luz del art. 4 del Reglamento 4/2009, que engloba tales obligaciones cuando derivan de una relación familiar, de parentesco, matrimonio o afinidad (Vargas Gómez-Urrutia, 2017, p. 323). 


\section{Bibliografía}

ÁLVAREZ GONZÁLEZ, Santiago. Orden público europeo versus orden público internacional de cada Estado. La gobernanza del interés público global, XXV Jornadas de Profesores de Derecho internacional y relaciones internacionales. Tecnos. Madrid, 2015.

ARENAS GARCÍA, Rafael. Principios inspiradores del sistema actual de competencia judicial internacional en materia de persona y familia, en GUZMÁN ZAPATER, Mónica y ESPLUGUES MOTA, Carlos (dirs.), HERRANZ BALLESTEROS, Mónica y VARGAS GÓMEZ-URRUTIA, Marina (coords.). Persona y familia en el nuevo modelo español de Derecho internacional privado. Tirant lo Blanch. Valencia, 2017.

CAMPUZANO DÍAZ, Beatriz. La propuesta de reforma del Reglamento 2201/2003: ¿se introducen mejoras en la regulación de la competencia judicial internacional?, en GUZMÁN ZAPATER, Mónica y ESPLUGUES MOTA, Carlos (dirs.), HERRANZ BALLESTEROS, Mónica y VARGAS GÓMEZ-URRUTIA, Marina (coords.). Persona y familia en el nuevo modelo español de Derecho internacional privado. Tirant lo Blanch. Valencia, 2017.

FERACI, Ornella. L'incidenza del nuovo regime europeo in tema di rapporti patrimoniali tra coniugi e parti di unioni registrate sull'ordinamento giuridico italiano e le interazioni con le novità introdotte dal d.lgs. 7/2017 attuativo della cd. legge Cirinnà. Osservatorio sulle fonti, Fascículo 2. Florencia, 2017.

FERNÁNDEZ ROZAS, José Carlos. Un hito más en la comunitarización del Derecho internacional privado: regímenes patrimoniales y efectos patrimoniales de las uniones registradas. La ley Unión Europea, nº 40. Wolters Kluwer. Madrid, 2016.

FERNÁNDEZ PÉREZ, Alberto. Mediación familiar transfronteriza en el ámbito europeo. La ley Derecho de familia, $\mathrm{n}^{\circ}$ 17. Wolters Kluwer. Madrid, 2018.

PEITEADO MARISCAL, Pilar, Competencia internacional por conexión en materia de régimen económico matrimonial y de efectos patrimoniales de uniones registradas. Relación entre los Reglamentos UE 2201/2003, 650/2012 y 1104/2016. Cuadernos de Derecho Transnacional, Vol. 9, $\mathrm{n}^{\mathbf{0}}$ 1. Universidad Carlos III: Área de Derecho Internacional Privado. Madrid, 2017.

QUINZÁ REDONDO, Juan Pablo. "La unificación -fragmentada- del derecho internacional privado de la Unión Europea en materia de régimen económico matrimonial: el Reglamento 2016/1103. Revista General de Derecho Europeo, nº 41. Iustel. Madrid, 2017.

QUINZÁ REDONDO, Juan Pablo. La cláusula de excepción del art. 26.3 del Reglamento 2016/1103 sobre régimen económico matrimonial, en GUZMÁN ZAPATER, Mónica y ESPLUGUES MOTA, Carlos (dirs.), HERRANZ BALLESTEROS, Mónica y VARGAS GÓMEZ-URRUTIA, Marina (coords.). Persona y familia en el nuevo modelo español de 
Derecho internacional privado. Tirant lo Blanch. Valencia, 2017.

QUINZÁ REDONDO, Juan Pablo y GRAY, Jacqueline. La (des) coordinación entre la propuesta de Reglamento de régimen económico matrimonial y los Reglamentos en materia de divorcio y sucesiones. Anuario Español de Derecho Internacional Privado, ${ }^{\circ} 13$. Iprolex. Madrid, 2013.

RODRIGUEZ BENOT, Andrés. La armonización del régimen económico matrimonial en la Unión Europea: la Propuesta de Reglamento de 2011, en ESPLUGUES MOTA, Carlos y PALAO MORENO, Guillermo (eds.), PENADÉS FONS, Manuel (coord.). Nuevas fronteras del derecho de la Unión Europea. Tirant lo Blanch. Valencia, 2012.

RODRIGUEZ BENOT, Andrés. Los efectos patrimoniales de los matrimonios y de las uniones registradas en la Unión Europea. Cuadernos de Derecho Transnacional, Vol. 11, $\mathrm{n}^{\circ} 1$. Universidad Carlos III: Área de Derecho Internacional Privado. Madrid, 2019.

RODRÍGUEZ VÁZQUEZ, Mª Ángeles. Una nueva fórmula para la supresión del exequátur en la reforma del Reglamento Bruselas I. Cuadernos de Derecho Transnacional, Vol. 6, $\mathrm{n}^{\circ} 1$. Universidad Carlos III: Área de Derecho Internacional Privado. Madrid, 2014.

VARGAS GÓMEZ-URRUTIA, Marina. El puzzle se complica. Efectos patrimoniales de las uniones registradas y Reglamento (UE) 2016/1104. Problemas de calificación y coordinación entre los instrumentos europeos conexos, en GUZMÁN ZAPATER, Mónica y ESPLUGUES MOTA, Carlos (dirs.), HERRANZ BALLESTEROS, Mónica y VARGAS GÓMEZURRUTIA, Marina (coords.). Persona y familia en el nuevo modelo español de Derecho internacional privado. Tirant lo Blanch. Valencia, 2017.

VINAIXA MIQUEL, Mónica. La autonomía de la voluntad en los recientes reglamentos UE en materia de regímenes económicos matrimoniales (2016/1103) y efectos patrimoniales de las uniones registradas (2016/1104). InDret, Universitat Pompeu Fabra, nº 2. Barcelona, 2017. 